\title{
Critical Thinking as a Way of Mastering the Strategies and Tactics of a Doctor's Speech Behavior
}

\author{
Osipenko T.A., ${ }^{1 * *}$ Turchevskaya B.K. ${ }^{2}$ \\ ${ }^{1}$ Institute of Linguistics and Intercultural Communication, I.M. Sechenov First Moscow State Medical University, \\ Moscow, Russia \\ ${ }^{2}$ Department of Philosophy and Social-Humanitarian Disciplines, Pacific National University, Khabarovsk, Russia \\ *Corresponding author. Email: tatianaossipenko@gmail.com
}

\begin{abstract}
This paper examines the problem of forming a doctor's speech behavior when working with patients. The article draws attention to the lack of academic discipline, which allows to introduce future doctors to the problems of communication in practice. Dialogue is considered as an effective method of "doctor-patient" partnership and as a way to form the critical thinking of a doctor. The article presents communication strategies and tactics of speech behavior of a doctor, ways of their implementation in a clinical conversation, some features of a consulting conversation. The necessity of critical thinking skills formation at the stage of higher professional medical education in the perspective of their further practical application in work with patients is substantiated. As a result of the analysis, using the example of teaching "Logic" (within the framework of "Philosophy") and "Foreign Language" disciplines, the possibility of familiarizing the future doctor with strategies and tactics of speech behavior in a clinical conversation is illustrated based on an interdisciplinary approach.
\end{abstract}

Keywords: critical thinking, speech behavior, clinical conversation, medical discourse, communicative approach, communicative-pragmatic approach

\section{INTRODUCTION}

The importance of doctor-patient skills in building an effective doctor-patient dialogue is linked to the increased interest of the patient in deciding on their treatment, which leads to questioning the doctor's recommendations and non-compliance with treatment instructions. The consequences of this may be the patient's deteriorating health, complaints about the low level of professional training of medical personnel, a decrease in the prestige of the doctor, dissatisfaction with the quality of medical care in general, which follows from the evaluation of anonymous surveys of patients about the quality of services provided by medical organizations. The questionnaire can be filled in by anyone on the website of the Ministry of Health of the Russian Federation.

As information is available on the Internet, patients often come with a number of questions that they want an answer to. This requires from the doctor not only high professional skills, but also mastering various tactics of communicative behavior, ability to critically assess the situation. It is necessary to change the models of communicative actions, both in terms of prescribed therapy and in terms of changing communicative behaviour.

\section{METHODS AND MATERIALS}

The purpose of this article is to familiarize medical students with the options of conducting a dialogue in a consultative conversation.
The topicality of this topic is caused, firstly, by the change in the status of the patient: his greater awareness (not always based on reliable sources), the desire to take an active part in decision-making about the methods of treatment with the doctor. Secondly, a change in the set of competences that the doctor has to possess. In addition to professional skills, they need to learn not only basic communication, argumentation and persuasion skills, but also the principles of critical thinking.

The following objectives were set to achieve the objective: 1) to consider some strategies and tactics of the doctor's speech behavior, 2) to reveal the role of critical thinking in situations of implementation of these strategies and tactics in the dialogue with the patient, 3) to analyze the relationship between critical thinking and speech behavior of medical students.

To solve the tasks, the work uses a communicative and pragmatic analysis of the institutional medical discourse and a descriptive approach of the method of interpretation and systematization.

\section{RESULTS}

Availability of knowledge on medical topics helps to "turn" the patient into an active participant in medical discourse. "Activity" in this case means not only interested participation in the dialogue during the examination, but also willingness to share responsibility for the decision taken with the doctor (ideally, but in practice the patient often does not realize and does not 
recognize his or her responsibility for the decision taken jointly). Koefer A. and Albus K. introduce the concept of the so-called "emancipated" patient, i.e. an equal, wellinformed patient whose education allows for participation in the decision-making process. In medical discourse, the term "responsible patient" is being developed to become an analogue of "responsible citizen" [1, 14].

The communicative model of the doctor's behavior plays an important role in establishing contact with the patient today. Since patients often have distorted subjective knowledge about the nature of their illness, the doctor's task is to be able to lead the patient into an open, trusting dialogue that will form the basis for guidelines for successful therapy. It is also important to pay attention to the way in which information is presented without upsetting the balance between its content and the patient's possible perception of it.

Depending on the purpose of communication and the stage of treatment, the doctor should choose the strategy that will most effectively achieve a positive result of treatment. Currently, three main strategies are best described and justified in the literature: diagnostic, treatment and recommending [11].

Each strategy is characterized by certain speech tactics. The implementation of a diagnostic strategy is best realized through the tactics of acquaintance, requesting specific information, rapprochement or explanation. A healing strategy involves tactics of psychological regulation, comfort, reasoning, coaching, and argumentation. This strategy also includes the tactics of appealing to common sense, the tactics of deliberate silence, encouragement or delicacy, mild accusation, as well as tactics to maintain emotional balance. The implementation of a recommending strategy takes place through a tactic that focuses on the patient's material abilities [10, 12].

In addition to knowledge of strategies and tactics of speech behavior, the doctor himself needs to properly conduct the dialogue, in which the initial stage is particularly important. Closed-ended questions involve one-size-fits-all yes/no answers and leave little "space" for the patient to participate in the dialogue, so it is preferable to use open-ended questions that begin with the phrase "tell me about..." or the use of non-verbal signals that may encourage the patient to organize their own request. The patient's task is to describe his or her complaints, symptoms, and feelings in as much detail as possible, as well as to express his or her assumptions and knowledge about the issue. The task of the doctor is to listen actively, if necessary, ask clarifying questions, direct the dialogue in the right direction, accompanied by non-verbal signs of understanding and encouragement [3].

It often happens that a patient who has entered into a dialogue with a doctor is too keen to talk about his or her illnesses, too emotional, too upset, or too aggressive. Because of this, he or she chooses all the time limits set by the standard for one patient. Therefore, the doctor's task is to choose the most productive pace of conversation, without wasting time during an appointment.
It is not enough to choose the right strategy and tactics of speech behavior. It is necessary to be able to consciously assess the situation and promptly take measures to correct the situation, using the communication skills acquired as a result of training. Constructiveness and reasonableness are some of the most important skills for a physician, based on critical thinking.

It is critical thinking that contributes, on the one hand, to the development of general competencies, such as mastery of the culture of communication, the ability to logically build oral and written speech. This is not least due to a targeted reflection on the dynamics of society and the changing role of the patient, the recognition and acceptance of social and personal issues. On the other hand, critical thinking involves the introduction of new skills into professional competences, such as the ability to critically analyze the situation and revise existing knowledge and experience, to interpret the patient's verbal behavior and, on this basis, to model their verbal behavior [4].

Patients do not trust simple imperative statements. Argumentatized and logically constructed information helps to establish a trusting contact between the patient and the doctor, which makes them equal participants in the dialogue, does not allow inflicting psychological trauma when expressing disagreement or criticism of the patient's non-professional point of view (in the case when the patient misinterprets professional literature, which he had read on the Internet before consulting with a specialist and has already made his own diagnosis).

Based on years of experience, most doctors intuitively acquire critical thinking skills derived from personal experience in conflict resolution. They have several speech and behavioural strategies in stock for both specific situations and stereotypical types of patients.

Critical thinking is formed while studying in a medical university, as the basis for such thinking is based on the known laws of logic, which after study often remain unclaimed in practice theory. The amount of knowledge that needs to be learned in training is so great that the introduction of an additional discipline to master communication strategies and tactics of speech behavior may be an enormous burden for the student. Here, an interdisciplinary approach to learning is appropriate, with special attention to the teaching of such subjects as Philosophy, Logic, and Foreign Languages.

The philosophical section "Logic" can become a methodological basis for studying strategies and tactics of speech behavior, as it allows, on the basis of critical thinking, to solve conflict situations, analyze errors, and identify their place and role in decision-making. Critical thinking implies the ability to work in terms, to clearly articulate thoughts and, in the case of lack of information, to ask additional or accompanying questions, to anticipate the answers of the interlocutor and to model alternative relevant answers, to identify errors and inaccuracies in the patient's arguments [8].

Studying the basic principles of critical thinking is useful for medical students because the theory of reasoning in critical thinking takes into account the 
emotional state and mood of the interlocutor. Questioning old facts leads to constant revision of previously received information, the ability to assess it, which is very important for future doctors, because not always the same therapy helps everyone without exception. You need to be able to think flexibly in order to test your views on consistency and consistency of facts in a new situation. If necessary, the physician should be able to identify a new alternative solution $[5,6]$.

Studying the theory of strategies and tactics of speech behavior without practice is a waste of time. Formation and assimilation of the rules of speech behavior requires practical consideration of possible conflict situations that arise during consulting conversations. The development of a logical framework for communication involves the following:

- application of logic laws directly in communication, i.e. orientation of logical knowledge on practical application;

- analysis of different types of errors that make communication difficult (improperly constructed reasoning or argumentation);

- constructing questioning suggestions to position and talk to the patient, while maintaining its leading role in dialogue, to make prompt decisions in conflict situations and to implement strategies of persuasion $[4,8]$.

Speech training is also possible in foreign language classes, provided that the trainee already has basic knowledge of communication and has an understanding of the basic strategies and tactics of speech behavior of the doctor. This can only be achieved through an interdisciplinary approach, i.e. "consensus" on the issue in a number of disciplines, such as Philosophy and Foreign Languages.

With a communicative competence, the learner can easily master the dialogue method of language learning. This method has been known for quite a long time, but is rarely used in the training of medical students for whom communication skills are an essential competence. Distinctive feature of dialogue speech is its clichy nature, which can be a huge advantage when learning a foreign language, because this approach does not consider individual words, but often whole sentences that are placed, albeit in a simulated situation, but very close to reality [13]

It is expedient to consider dialogue not only as a way to organize training, but also as a factor in the development of personal qualities of students. Building a lesson on a dialogue system can become a source of personal experience and a factor actualizing the ability to reflect and business criticism [7, 14].

At the initial stage of mastering the dialogue method, it is necessary to acquaint students with already available examples of dialogues, which include standard speech statements. Examples include dialogues on the topic "Primary reception", "Consulting conversation", "Allergological anamnesis", "Hereditary anamnesis",
"Anamnesis of the nature of nutrition", "Recommendations on taking drugs", etc. Work with the text includes reading and translation of dialogues, their analysis, identification of typical grammatical structures, words, word combinations and sentences, drawing up dialogues on such topics and their reproduction, collective discussion of the content of the dialogue and language correction.

Examples of "conflict dialogues" (the patient's disagreement with the prescribed treatment algorithm, the absence of coupons in the registration for outpatient appointments) and dialogues in which the doctor must report unpleasant news (for example, to inform about the nature of possible complications, to report the presence of cancer or the need for surgery) are recommended to get acquainted after mastering standard speech situations. At this stage, students may be asked to put together a sequence of questions and lines to help resolve the situation.

Special attention should be paid to conflict conversations or non-standard situations, which are always more interesting. In the event of a conflict situation, the doctor should 1. assess the psycho-emotional state of the patient and his or her ability to conduct a dialogue, 2 . listen carefully to the patient and clarify the missing information, 3. calm down, express support and readiness to solve the problem, 4. state his or her position and propose ways of solving the problem, 5 . coordinate the algorithm of further actions with the patient, 6 . ask if there are still any questions, 7 . be able to politely interrupt the conversation if necessary, 8 . sum up the conversation and say goodbye. When practicing "conflict dialogues", the ability to ask questions is gained [7, 14].

The "advanced" stage of mastering the dialogue method when studying a foreign language can be considered the ability of students to work with the proposed "situation tasks". Students are given a card describing a typical or problematic situation that occurs during an appointment (for example, a patient's disagreement with the proposed treatment methods or a request for a more detailed description of additional treatment options). The trainees are divided into two groups. The conditional "patient" forms an algorithm for his or her speech behavior, and the "doctor" tries to predict what questions the "patient" may have and what options he or she can offer for conflict resolution. The dialogue is then lost in pairs. Students make their own assessment of how well they have managed to predict the situation and choose their speech behavior, and adjustments are made together, which may affect both the content side of the dialogue and the language side. The dialogue is then "lost" in front of the group and the content and language side of the dialogue is discussed collectively once again.

The use of dialogue methods in foreign language classes at a professional medical school encourages students to model the real speech situation already at the stage of education. Such creative and improvisational dialogue construction also allows practicing grammatical structures typical for spoken language. The development of dialogues becomes a starting point for a meaningful conversation. At the same time, it is necessary to observe 
some interval in carrying out of such type of lessons: lessons on the basis of dialogue should become a part of mastering of a material, but should not occupy all lessons on a foreign language $[2,9]$.

\section{CONCLUSION}

The need to master strategies and tactics of speech behavior by students of medical educational organizations is due to changing approaches to the status of the patient. At present, there is a tendency to involve the patient in making decisions about their treatment methods. Patient satisfaction with the quality of service provided often depends on successful communication. Establishing contact with the patient starts with asking questions and understanding the issues that the patient is concerned about. The doctor's ability to provide clear information about treatment options and to apply the arguments convincingly when necessary is important. This skill is related to understanding the basics of critical thinking and knowledge of strategies and tactics of speech behavior.

The need to master strategies and tactics of speech behavior by students of medical educational organizations is due to changing approaches to the status of the patient. Dialogue is seen not only as a strategy of the doctor's behavior, which, if properly implemented in a consultation conversation, leads to positive treatment results, but also as a means of forming critical thinking, which is necessary to achieve professional goals. Critical thinking and dialogue skills can also be formed on the basis of years of experience working with patients, but it is possible and necessary to reduce the time for their formation, thus reducing professional risks.

Based on an analysis of sources on this issue, as well as on practical experience, it can be concluded that strategies and tactics of speech behavior should be studied at the initial stage of mastering the profession of doctor. The introduction of an effective "patient care" approach into the curriculum is most effective at an interdisciplinary level. For purposeful formation of skills of speech behavior of the doctor it is expedient to use disciplines "Philosophy" and "Foreign languages".

\section{REFERENCES}

[1] A. Koerfer, Ch. Albus, Dialogische Entscheidung zwischen Arzt und Patient, Handbuch, Sprache in der Medizin, Band 11, Walter de Gruyter GmbH, Berlin, Boston, 2015, pp. 116-134.

[2] B. Shekhtman, How to teach speaking foreign Languages effectively, Dialoge on lang. institut. 25 (2015) 3-19.
[3] Th. Spranz-Fogasy, M. Becker, Beschwerdenexploration und Diagnosemitteilung im ärzlichen Erstgespräch, Handbuch, Sprache in der Medizin, Band 11, Walter de Gruyter GmbH, Berlin, Boston, 2015, pp. 93-115.

[4] B.K. Turchevskaya, Critical thinking as an educational technology, Modern problems of science and education, 2015, 2-2, p. 81-84.

[5] V.N. Bryushinkin, Generalized systemic model of argumentation, Argumentation and Interpretation. Research in logic, history of philosophy and social philosophy: collection of scientific articles, 2006, p. 9-17.

[6] E.E. Ivunina, On different approaches to the concept of critical thinking, Young Scientist, 2009, 11, p. 170-174

[7] I.A. Khrushch, N.A. Berezenovskaya, T.N. Alyko, Constructive overcoming of conflicts, Minsk: BSMU, 2013.

[8] I.N. Griftsova, G.V. Sorina, Ideas of Critical Thinking through the Prism of Historical and Philosophical Soap, Democracy in Russia and Europe: a Philosophical Dimension. Materials of the international conference "Philosophical problems of a democratic society", 2003, p. 65-80.

[9] M.V. Pyanova, On the development of critical thinking in the study of a foreign language among students of non-linguistic universities, Bulletin of Science and Education, 2018, 5 (41) volume 1, p. 98102.

[10] M.I. Barsukova, D.L. Dorogoikin, T.V. Kochetkova, The problem of communication along the line "doctor - patient", Bulletin of medical Internet conferences, 2016, 1, volume 6, p. 216-217.

[11] M.I. Barsukova, Medical discourse: strategies and tactics of a doctor's speech behavior, Saratov, 2007.

[12] N.A. Dzaraeva, R.A. Rogozhnikova, Strategies and tactics of a physician's speech behavior, Bulletin of the Perm State Humanitarian Pedagogical University. Series No. 1. Psychological and pedagogical sciences, 2014, p. 47-53.

[13] N.V. Antonova, Zh.N. Shmeleva, Formation of communicative competence in the study of English by students of a non-linguistic university, Bulletin of KrasGAU, 2, 2014, p. 240-244.

[14] Yu.V. Shevtsova, A.V. Emelina, E.A. Zakharov, On the issue of conflicts between doctors and patients and the psychological readiness of doctors to work, Medical Almanac, 5, (2011) 36-39. 